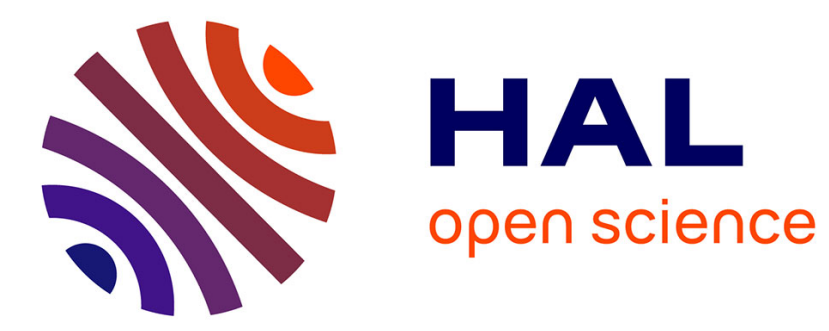

\title{
Synthesis of Lactams by Reductive Amination of Carbonyl Derivatives with omega-Amino Fatty Acids under Hydrosilylation Conditions
}

Satawat Tongdee, Duo Wei, Jiajun Wu, Chakkrit Netkaew, Christophe Darcel

\section{- To cite this version:}

Satawat Tongdee, Duo Wei, Jiajun Wu, Chakkrit Netkaew, Christophe Darcel. Synthesis of Lactams by Reductive Amination of Carbonyl Derivatives with omega-Amino Fatty Acids under Hydrosilylation Conditions. European Journal of Organic Chemistry, 2021, 2021 (40), pp.5536-5539. 10.1002/ejoc.202100719 . hal-03331215

\section{HAL Id: hal-03331215 \\ https://hal.science/hal-03331215}

Submitted on 16 Sep 2021

HAL is a multi-disciplinary open access archive for the deposit and dissemination of scientific research documents, whether they are published or not. The documents may come from teaching and research institutions in France or abroad, or from public or private research centers.
L'archive ouverte pluridisciplinaire HAL, est destinée au dépôt et à la diffusion de documents scientifiques de niveau recherche, publiés ou non, émanant des établissements d'enseignement et de recherche français ou étrangers, des laboratoires publics ou privés. 


\title{
Synthesis of Lactams by Reductive Amination of Carbonyl Derivatives with $\omega$-Amino Fatty Acids under Hydrosilylation Conditions
}

\author{
Satawat Tongdee, ${ }^{\dagger[a]}$ Duo Wei, ${ }^{+[a]}$ Jiajun Wu, ${ }^{\dagger[a]}$ Chakkrit Netkaew, ${ }^{[a]}$ and Christophe Darcel ${ }^{\star[a]}$ \\ Dedication ((optional))
}

\begin{abstract}
An efficient method for the preparation of lactams from $\omega$ amino fatty acids under hydrosilylation is described. A variety of lactams such as pyrrolidinones, piperidinones and 2-azepanones were selectively synthesised in moderate to excellent yields (29 examples, up to $95 \%$ isolated yields) with a good functional group tolerance. Noticeably, no metallic based catalyst was required to perform such transformation.
\end{abstract}

Amides, and more particularly lactams are crucial and versatile intermediates building blocks in pharmaceutical chemistry, polymer and synthetic organic chemistry. ${ }^{[1]}$ Particularly pyrrolidinones, piperidinones and 2-azepanones are present in a large class of natural products and biologically active molecules, among the most sold drugs. ${ }^{[2]}$ (Figure 1) Indeed, pyrrolidinones are usually base motifs in the drug racetams such as Levetiracetam, classically used for treatment of focal epilepsy in adults, or Lenatidomide for the treatment of multiple myeloma. Piperidinone motif is also widely met in pharmaceuticals like Apixaban used to prevent venous thromboembolism. Drugs based on caprolactam moiety are also popular as illustrated by Benzepril used to treat high blood pressure and heart failure.
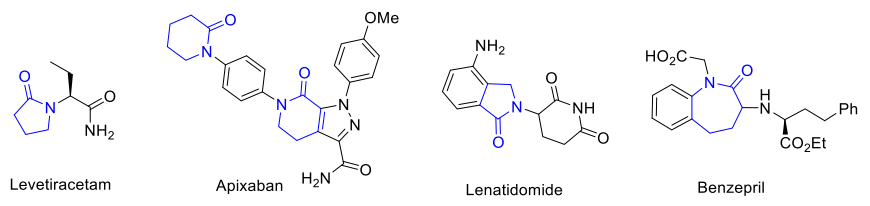

Figure 1. Selected examples for lactams used in pharmaceuticals.

Thus, this topical context still prompts to prepare cyclic amides in an efficient and simple way. Indeed, among the numerous methodologies, ${ }^{[3]}$ reductive ones were efficiently developed. ${ }^{[4]}$ Lactams can be obtained from the corresponding cyclic imides by selective reduction with red-Al (sodium bis(2methoxyethoxy)aluminium hydride) or $\mathrm{NaCNBH}_{3},{ }^{[5]}$ hydrogenation using ruthenium based catalysts, ${ }^{[6]}$ TBAF or potassium hydroxide catalysed hydrosilylation ${ }^{[7]}$ or electrochemical reduction. ${ }^{[8]}$ Alternatively, $\mathrm{N}$-substituted lactams

[a] S. Tongdee, Dr. D. Wei, J. Wu, C. Netkaew, Prof. Dr. C. Darcel Univ Rennes, CNRS, ISCR

(Institut des Sciences Chimiques de Rennes)

UMR 6226, F-35000, Rennes, France

E-mail: christophe.darcel@univ-rennes1.fr

https:// iscr.univ-rennes 1 .fr/christophe-darcel

$\dagger \quad$ Authors contributed equally to this work.

Supporting information for this article is given via a link at the end of produced from keto-acids (e.g. levulinic acid) and primary amines under reductive conditions were reported in both catalytic and catalyst-free conditions such as hydrogenation, ${ }^{[9]}$ hydrogen transfer using formic acid ${ }^{[10]}$ or hydrosilylation. ${ }^{[11]}$ Similarly, $\mathrm{Al}(\mathrm{OTf})_{3}$-catalysed hydrosilylation of keto-amides led to the corresponding pyrrolidinones and piperidinones. ${ }^{[12]}$ Noticeably, the preparation of lactams can be also conducted starting from amino alcohols. ${ }^{[13]}$

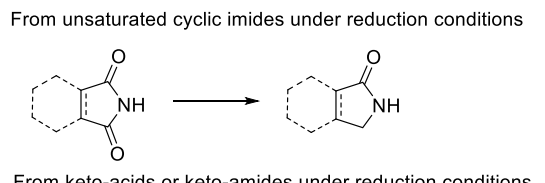

From keto-acids or keto-amides under reduction conditions
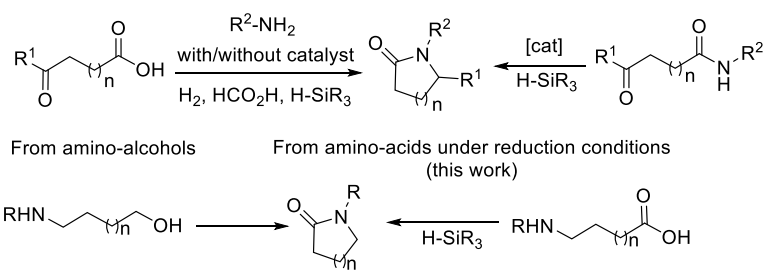

Scheme 1. Representative pathways for lactam synthesis under reductive conditions.

Recently, we have developed an iron-catalysed one-pot preparation of $\mathrm{N}$-substituted cyclic amines via reductive amination of carbonyl derivatives with $\omega$-amino fatty acids under hydrosilylation conditions. ${ }^{[14]}$ During this study, we identified that the first step of the synthesis leading to the lactams did not require iron catalyst. Thus, we report an efficient and selective one-pot preparation of $\mathrm{N}$-substituted lactams (including pyrrolidinones, piperidinones and 2-azepanones) via reductive amination of carbonyl derivatives with $\omega$-amino fatty acids by hydrosilylation (Scheme 1).

We began our initial optimization experiments based on the previous results in which we have identified that the formation of the piperidinone $3 \mathbf{a}$ can be obtained selectively starting from 5aminopentanoic acid 2 and benzaldehyde 1a by reaction with 5 equiv. of phenylsilane at $100{ }^{\circ} \mathrm{C}$ for $3 \mathrm{~h}$ in toluene (Table 1 , entry 1). When decreasing the quantity of silane from 5 to 1 equiv., and the temperature from $100{ }^{\circ} \mathrm{C}$ to $\mathrm{RT}$, we observed a huge decrease of activity and selectivity (entries 2 and 3 ). We then studied the influence of the solvent. Performing the reaction at RT in the presence of 1 equiv. of phenylsilane, in dimethylcarbonate (DMC), ethyl acetate, or water led to low conversions and selectivities (entries 4-6). 
Table 1. Optimization of the reaction parameters. ${ }^{[a]}$

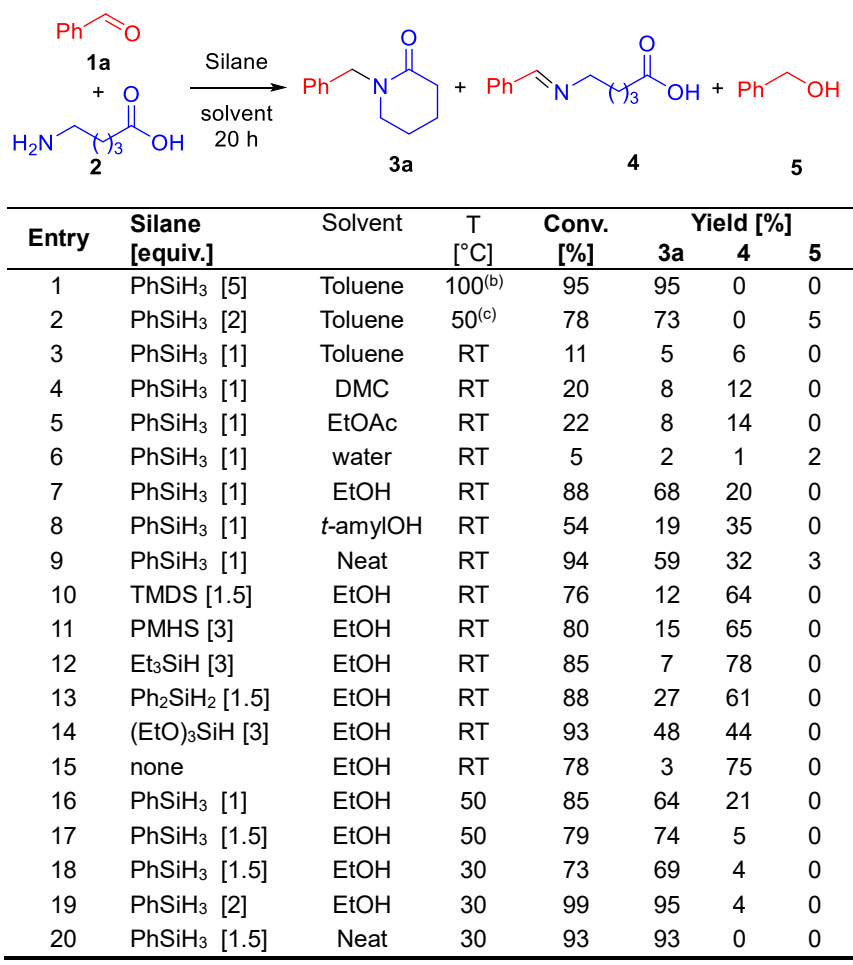

[a] General reaction conditions: $1 \mathrm{a}(0.1 \mathrm{mmol}), 2(0.1 \mathrm{mmol})$, hydrosilane, solvent $(0.5 \mathrm{~mL})$ at $\mathrm{RT}-100{ }^{\circ} \mathrm{C}$ for $20 \mathrm{~h}$ under air atmosphere. The conversions and yields were determined by ${ }^{1} \mathrm{H}$ NMR spectroscopy; [b] $3 \mathrm{~h}$; [c] $4 \mathrm{~h}$.

Using protic solvents such as ethanol or $t$-amylalcohol or neat conditions permitted to increase the conversions, but with a modest selectivity (entries 7-9). Afterwards, different hydrosilanes were evaluated in order to study the selectivity of the reaction. Using TMDS (1,1,3,3-tetramethyldisiloxane, 1.5 equiv.) and PMHS (polymethylhydrosiloxane, 3 equiv.), good conversions were obtained (up to $80 \%$ ) but the imine 4 was detected as the major product, with $12-15 \%$ of piperidinone $3 \mathbf{a}$ (entries 10 and 11 ). When using triethylsilane, diphenylsilane, or triethoxysilane, similar results in terms of activity and selectivity were obtained (entries 12-14). Noticeably, in the absence of hydrosilanes, small amount of $3 \mathbf{a}$ was obtained (3\%), the main product being the imine $4(75 \%$, entry 15$)$, highlighting the crucial importance of hydrosilane in this transformation. Having identified phenylsilane as the best hydrosilane, its ratio was then studied. The use of 2 equiv. of $\mathrm{PhSiH}_{3}$ in ethanol at $30{ }^{\circ} \mathrm{C}$ permitted to obtain piperidinone $3 \mathbf{a}$ in $95 \%$ yield, with trace amount of imine 4 . Similarly, under neat conditions, $\mathbf{3 a}$ was obtained specifically in $93 \%$ yield (entries $16-20$ ).

With our optimized conditions in hand, we then explored the substrate scope for the reductive amination of carbonyl derivatives with $\omega$-amino fatty acids into $\mathrm{N}$-substituted lactams (Tables 2 and 3). First, the reaction of 4-aminobutanoic acid 6 with several aldehydes was examined. Benzaldehyde was smoothly converted into the corresponding $\mathrm{N}$-substituted pyrrolidinone $7 \mathrm{a}$ in $95 \%$ isolated yield. Using substituted benzaldehyde by donating groups such as $p$-anisaldehyde or $p-(N, N-$ dimethylamino)benzaldehyde led to the corresponding pyrrolidinones $\mathbf{7 b}-7 \mathrm{c}$ in 83 and $42 \%$ yields, respectively. Noticeably, starting from the hindered mesitaldehyde, the corresponding product $\mathbf{7 d}$ was isolated in moderate yield $(67 \%)$. The transformation also tolerated halides $(\mathrm{F}, \mathrm{Cl}, \mathrm{Br})$ affording the derivatives $\mathbf{7 e - 7 g}$ in $82-89 \%$ yields.

Table 2. Scope of the synthesis of pyrrolidinones by reductive amination of carbonyl derivatives with 4-aminobutanoic acid. [a]
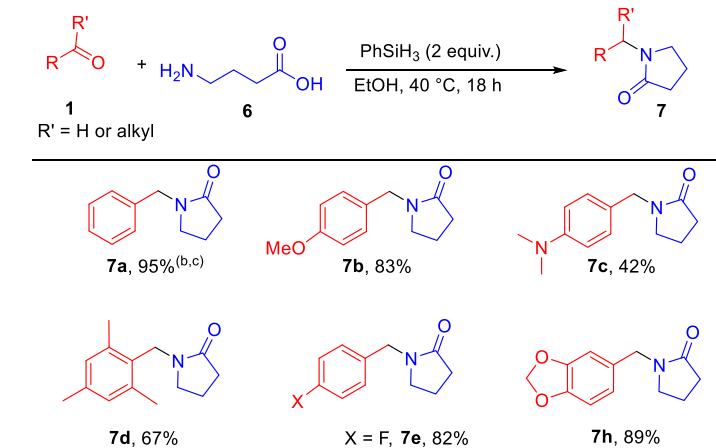

$X=F, 7 e, 82 \%$
$X=C l, 7 f, 89 \%$

7h, $89 \%$
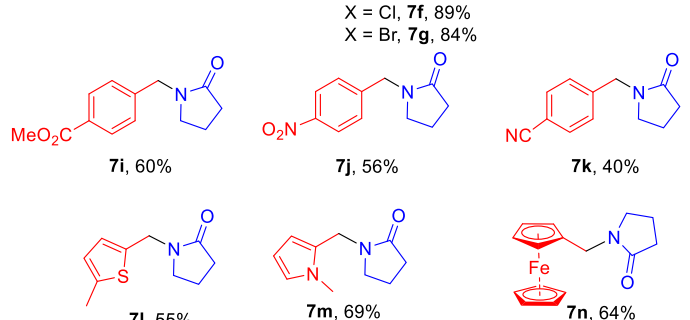

7j, $56 \%$

$7 \mathbf{k}, 40 \%$
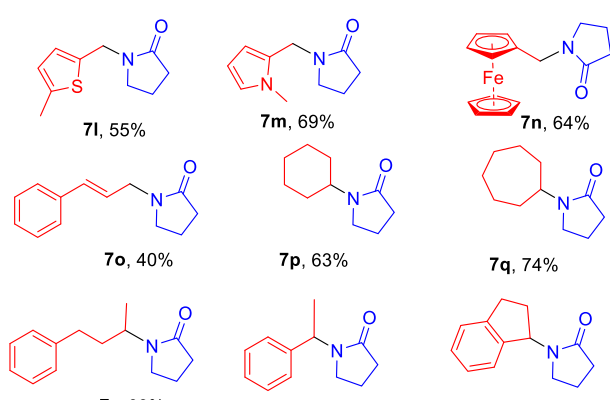

$7 \mathrm{p}, 63 \%$

7q, $74 \%$

$7 \mathrm{r}, 68 \%$
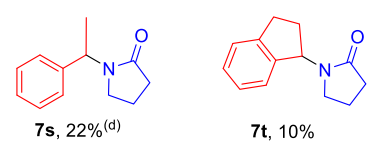

[a] General reaction conditions: 1 ( $0.6 \mathrm{mmol}), 6$ ( $0.5 \mathrm{mmol}), \mathrm{PhSiH}_{3}$ (2 equiv.) and ethanol $(0.5 \mathrm{~mL}), 40^{\circ} \mathrm{C}, 18 \mathrm{~h}$; Isolated yields of 7 are shown; [b] Reaction for $18 \mathrm{~h}$ in methanol, $69 \%$ NMR-yield, in ethanol, $60 \%$ NMR yield, in isopropanol, $56 \%$ NMR yield. [c] Reaction for $24 \mathrm{~h}$. [d] Reaction at $80^{\circ} \mathrm{C}$.

Interestingly, benzodioxole, an important building block in pharmaceuticals can be easily linked to pyrrolidinone core leading to $7 \mathrm{~h}$ in $89 \%$ yield.

It should be also underlined that pyrrolidinones bearing reducible functional groups such as carboxylic ester (7i) nitro (7j) and cyano (7k) could be synthesized in moderate isolated yields (40-60\%), exhibiting an interesting functional group tolerance of this transformation. In addition, hetero-aromatic aldehydes based on thiophene and pyrrole motifs were selectively converted to 7I$7 \mathrm{~m}$ in 55 and $69 \%$ yields, respectively. Pyrrolidinone $\mathbf{7 n}$ bearing a ferrocenyl substituent was also produced in $64 \%$ yield. Interestingly, starting from cinnamaldehyde, the corresponding allylic pyrrolidinone 70 was isolated in $40 \%$ yield, without observation of by-products resulting from the hydrosilylation of the 
conjugated $\mathrm{C}=\mathrm{C}$ bond. Noticeably, when the reaction was performed with an alkanal such as 3-phenylpropanal under similar conditions, the corresponding 1-(3-phenylpropyl)pyrrolidin-2-one (7u) was obtained with only $10 \%$ isolated yield.

The reaction of 4-aminobutanoic acid was also evaluated with ketones. Noticeably, cyclohexanone and cycloheptanone reacted nicely leading to the corresponding $\mathrm{N}$-cyclohexyl and $\mathrm{N}$ cycloheptyl-pyrrolidinones $7 p$ and $7 q$ with 63 and $74 \%$ yields, respectively. Similarly, starting from 4-phenylbutan-2-one, 7r was isolated in $68 \%$. By contrast, when conducting the reaction with acetophenone and 1-indanone, the corresponding pyrrolidinones $7 \mathrm{~s}$ and $7 \mathrm{t}$ were obtained in poor yields ( 22 and $10 \%$, respectively).

Next, this reductive amination was extended to 5aminopentanoic acid 2 in order to synthesise the corresponding piperidinones $\mathbf{3}$ (Table 3).

Table 3. Scope of the synthesis of piperidinones 3 and 2-azepanones 9 by reductive amination of carbonyl derivatives with 5 -aminopentanoic acid and 6-aminohexanoic acid, respectively. ${ }^{[a]}$

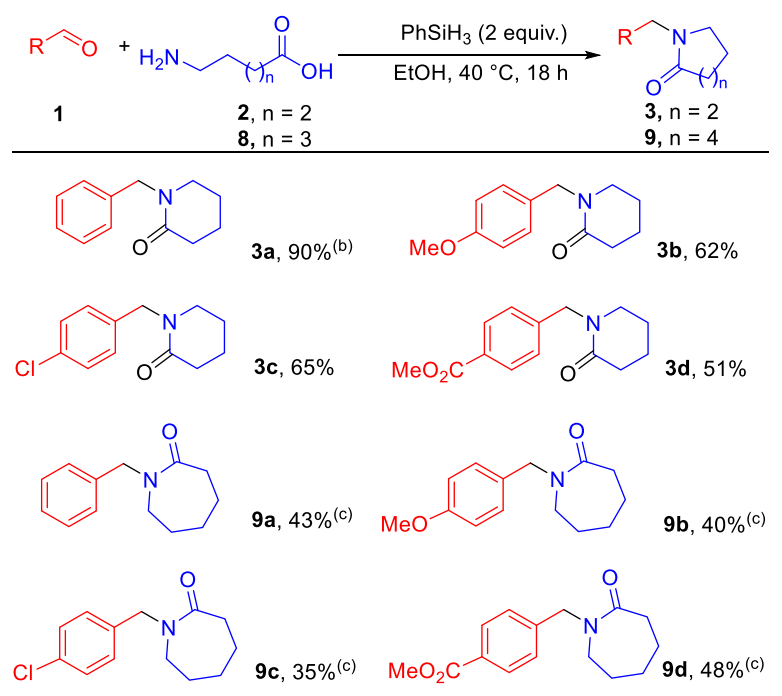

[a] General reaction conditions: $1(0.6 \mathrm{mmol}), 2$ or $8(0.5 \mathrm{mmol}), \mathrm{PhSiH}_{3}$ (2 equiv.) and ethanol $(0.5 \mathrm{~mL}), 40{ }^{\circ} \mathrm{C}, 18 \mathrm{~h}$. Isolated yields of 3 or 9 are shown; [b] Reaction for $24 \mathrm{~h}$; [c] Reaction for $48 \mathrm{~h}$.

In the selected examples represented in Table 3, p-methoxy- and $p$-chloro- substituted benzaldehydes led to the corresponding piperidinones $\mathbf{3 b}$ and $\mathbf{3 c}$, in 62 and $65 \%$ yields, respectively. Methyl ester reducible functional group was also tolerated affording $\mathbf{3 d}$ in $51 \%$ yield. 6 -Aminohexanoic acid 8 was then evaluated to prepare 2-azepanones 9 as shown in Table 3. Thus, benzaldehyde, $p$-anisaldehyde and $p$-chlorobenzaldehyde furnished $9 a-9 c$ in moderate yields (35-43\%). Methyl 4formylbenzoate can be also transformed to the corresponding 2azepanone $9 \mathrm{~d}$ in $48 \%$ without alteration of the ester moiety. Interestingly, this transformation resulted from (i) the imine formation by condensation of amine with carbonyl derivatives, (ii) following by its reduction and finally an amidation of the acid moiety. Importantly, this transformation seems to be specific to $\omega$ amino fatty acid derivatives. Indeed, the reaction of methyl 4aminobutyric ester with benzaldehyde under similar conditions did not lead to the expected pyrrolidinones, but only to the corresponding imine. In order to have experimental evidences of the pathway of this sequential transformation, we performed the reaction of benzaldehyde with $n$-butylamine in ethanol at $40^{\circ} \mathrm{C}$ for $18 \mathrm{~h}$ (Table 4). In the absence of silane, only the condensation took place generating selectively the corresponding imine $\mathbf{1 0}$ (entry 1 ). In the presence of 2 equiv. of phenylsilane, 10 was still the main product with only trace amount of 11 , and 12 , resulting from the reductive amination and the double reductive amination of benzaldehyde, respectively (entry 2). By addition of 1 equiv. of carboxylic acid such as acetic acid, even if aldimine $\mathbf{1 0}$ was still obtained as the major compound, a significant amount of the derivatives resulting from reductive amination of benzaldehyde 11 and 12 were detected (70:21:9 ratio) (entry 3). Using a stronger acid such as TFA ${ }^{[15]}$ led to $\mathbf{1 1}$ and $\mathbf{1 2}$ in a 82:18 ratio (entry 4). These results clearly demonstrated that Brönsted acids such as carboxylic acids were helpful for the transformation of imines to lactams in the presence of hydrosilanes, via the reduction of the imines by hydrosilylation. ${ }^{[16,17]}$

Table 4. Experimental evidences for the mechanism pathway. ${ }^{[a]}$

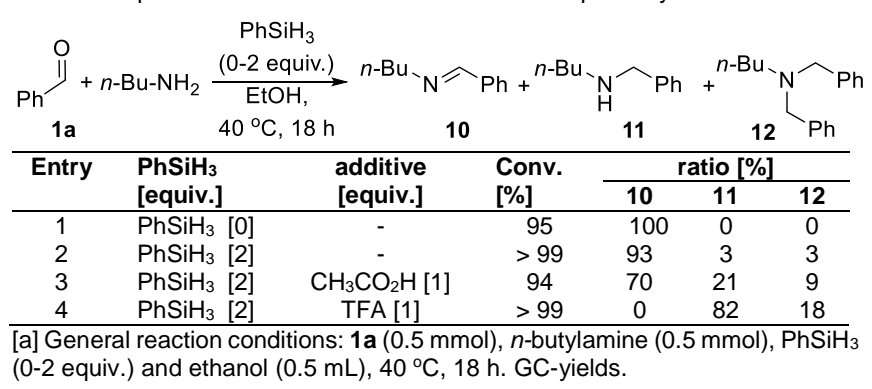

In summary, this contribution described a simple reductive procedure for the easy preparation of $\mathrm{N}$-substituted lactams (including pyrrolidinones, piperidinones and 2-azepanones) starting from $\omega$-amino fatty acids and a variety of carbonyl derivatives, via reductive amination performed under hydrosilylation conditions. The reaction proceeds with a nice functional group tolerance as reducible groups such as carboxylic ester, nitro, cyano and $\mathrm{C}=\mathrm{C}$ bond were well tolerated. Interestingly, this transformation involving a hydrosilylation step did not need an external catalyst, the acid moiety playing the role of internal activator during the reaction.

\section{Experimental Section}

Typical procedure for catalytic reductive amination of carbonyl derivatives with $\omega$-amino fatty acids leading to lactams. In a $20 \mathrm{~mL}$ Schlenk tube under air, $\omega$-amino fatty acids 2,6 or $8(0.5 \mathrm{mmol})$, carbonyl derivatives $1(0.6 \mathrm{mmol}), \mathrm{PhSiH}_{3}$ (123.4 $\mu \mathrm{L}, 2$ equiv.) and ethanol $(0.5 \mathrm{~mL})$ were stirred at $40{ }^{\circ} \mathrm{C}$ for $18 \mathrm{~h}$. After cooling to room temperature, the reaction mixture was dried under reduced pressure, and then the crude mixture was distilled using a bulb-to-bulb distillation apparatus. The distilled residue was then subjected to column chromatography (silica gel; ethyl acetate as the eluent) to afford the desired product. 


\section{Acknowledgements}

We thank the Université de Rennes 1, the Centre National de la Recherche Scientifique (CNRS) and the FR Increase. S.T. and C.N. thank the Fondation Rennes 1 for a fellowship. J. W. thanks the Chinese Scolarship Council for a PhD fellowship. We also thank Jérôme Ollivier for assistance for HR-MS analysis.

\section{Conflict of interest}

The authors declare no conflict of interest.

Keywords: $\omega$-Amino fatty acids $\cdot$ Hydrosilylation $\bullet$ Lactam $\bullet$ Reductive Amination • Metal catalyst Free

[1] For selected books, see: (a) Lactam-based polyamides, (Eds: R. Puffr V. Kubanek), CRC Press Inc. Boca Raton, Florida, 1991, Vol I; (b) M. I. Page, in The Chemistry of $\beta$-Lactams; (Ed.: M. I. Page), Blackie: Glasgow, 1992; pp 79-100; (c) J. Aszodi, D. A. Rowlands, P. Mauvais, P. Colette, A. Bonnefoy, M. Lampidas, Bioorg. Med. Chem. Lett. 2004 14, 2489-2492.

[2] For selected examples, see: (a) Natural Lactones and Lactams: Synthesis, Occurrence and Biological Activity; (Ed.:Janecki), Wiley-VCH: Weinheim, Germany, 2013; (b) G. F. Zha, K. P. Rakesh, H. M. Manukumar, C. S. Shantharam, S. Long, Eur. J. Med. Chem. 2019, 162 , 465-494; (c) R. D. Taylor, M. MacCross, A. D. G. Lawson, J. Med. Chem. 2014, 57, 5845-5859.

[3] Selected reviews or book chapters on the synthesis of lactams, see (a) M. A. Ogliaruso, J. F. Wolfe, in Synthesis of Lactones and Lactams, (Eds.: S. Patai and Z. Rappoport), John Wiley \& Sons, Inc.:West Sussex, England, 1993; pp 1-268. (b) M. B. Smith, Sci. Synth. 2005, 21, 647711; (c) C. R. Pitts, T. Lectka, Chem. Rev. 2014, 114, 7930-7953; (d) S. Hosseyni, A. Jarrahpour, Org. Biomol. Chem. 2018, 16, 6840-6852;.(e) J. Caruano, G. G. Muccioli, R. Robiette, Org. Biomol. Chem. 2016, 14 10134-10156; (f) L.-W. Ye, C. Shu, F. Gagosz, Org. Biomol. Chem. 2014 12, 1833-1845; (g) U. Nubbemeyer, Top. Curr. Chem. 2001, 216, 125196.

[4] D. Pingen, D. Vogt, Catal. Sci. Technol. 2014, 4, 47-52.

[5] (a) V. Bazant, M. Capka, M. Cerny, V. Chvalovsky, K. Kochloefl, M. Kraus, J. Malek, Tetrahedron Lett., 1968, 9, 3303-3306; (b) N. Kaplaneris, C. Spyropoulos, M. G. Kokotou, C. G. Kokotos, Org. Lett. 2013, 18, 580052803.

[6] (a) D. E. Patton, R. S. Drago, J. Chem. Soc. Perkin Trans. 1993,16111615; (b) R. Aoun, J.-L. Renaud, P. H. Dixneuf, C. Bruneau, Angew. Chem. Int. Ed. 2005, 44, 2021 -2023.
[7] (a) S. Das, D. Addis, L. R. Knöpke, U. Bentrup, K. Junge, M. Beller, Angew. Chem. Int. Ed. 2011, 50, 9180-9184; (b) G. Ding, C. Li, Y. Shen, B; Lu, Z. Zhang, X. Xie, Adv. Synth. Catal. 2016, 358, 1241 1250.

[8] Y. Bai, L. Shi, L. Zheng, S. Ning, X. Che, Z. Zhang, J. Xiang, Org. Lett. 2021, 23, 2298-2302.

[9] (a) Z. Xu, P. Yan, H. Jiang, K. Liu, Z. C. Zhang, Chin. J. Chem . 2017 35, 581-585; (b) S. Wang, H. Huang, C. Bruneau, C. Fischmeister, ChemSusChem 2017, 10, 4150-4154; (c) C. Chaudhari, M. Shiraishi, Y. Nishida, K. Sato, K. Nagaoka, Green Chem. 2020, 22, 7760-7764; (d) A B. Raut, V. S. Shende, T. Sasaki, B. M. Bhanage, J. Catal. 2020, 383, 206-214;

[10] (a) Y. B. Huang, J. J. Dai, X. J. Deng, Y. C. Qu, Q. X. Guo, Y. Fu, ChemSusChem 2011, 4, 1578-1581; (b) Y. Wei, C. Wang, X. Jiang, D. Xue, J. Li, J. Xiao, Chem. Commun. 2013, 49, 5408-5410; (c) S. Wang, H. Huang, C. Bruneau, C. Fischmeister, Catal. Sci. Technol. 2019, 9 , 4077-4082

[11] (a) Y. Ogiwara, T. Uchiyama, N. Sakai, Angew. Chem. Int. Ed. 2016, 55 1864-1867; (b) C. Wu, X. Luo, H. Zhang, X. Liu, G. Ji, Z. Liu, Z. Liu Green Chem. 2017, 19, 3525-3529; (c) M. C. Fu, R. Shang, W. M Cheng, Y. Fu, Angew. Chem. Int. Ed. 2015, 54, 9042-9046; (d) D. Wei, C. Netkaew, C. Darcel, Adv. Synth. Catal. 2019, 361, 1791-1796; (e) J. Wu, S. Tongdee, Y. Ammaiyappan, C. Darcel, Adv. Synth. Catal. 2021, doi: 10.1002/adsc.202100500; (f) D. A. Roa, J. J. Garcia, Inorg. Chim. Acta, 2021, 516, 120167; (g) T. Wang, H. Xu, J. He, Y. Zhang Tetrahedron 2020, 76, 131394

[12] J. Qi, C. Sun, Y. Tian, X. Wang, G. Li, Q. Xiao, D. Yin, Org. Lett. 2014, 16, 190-192.

[13] (a) J.-F. Soulé, H. Miyamura, S. Kobayashi, Asian J. Org. Chem. 2012, 1, 319-321; (b) B. P. Babu, Y. Endo, J.-E. Bäckvall, Chem. Eur. J. 2012 18, 11524-11527.

[14] D. Wei, C. Netkaew, V. Carré, C. Darcel, ChemSusChem 2019, 12 3008-3012.

[15] For selected references on TFA mediated hydrosilylation of carbonyl and carboxylic derivatives, see: (a) M. P. Doyle, C. T. West, J. Org. Chem 1975, 40, 3835-3838; (b) H. Mayr, B. Dogan, Tetrahedron Lett. 1997, 38 1013-1016; (c) M. Righi, A. Bedini, G. Piersanti, F. Romagnoli, G. Spadoni, J. Org Chem 2011, 76, 704-707; (d) J. P. Patel, A.-H. Li, H. Dong, V. L. Korlipara, M. J. M. J. Mulvihill, Tetrahedron Lett. 2009, 50, 5975-5977.

[16] For pioneer reports on TFA-promoted hydrosilylation of imines, see: Kursanov, D.N., Parnes, Z.N., Loim, NM. Synthesis, 1974, 633 and cited references.

[17] (a) Y. Li, J. A. Molina de La Torre, K. Grabow, U. Bentrup, K. Junge, S. Zhou, A. Brückner, M. Beller, Angew. Chem. Int. Ed. 2013, 52, 11577 11580; Angew. Chem. 2013, 125, 11791 - 11794; (b) M. P. Doyle, D. J. DeBruyn, D. A. Kooistra, J. Am. Chem Soc. 1972, 94, 3659-3661; (c) X Chen, Y. Deng, K. Jiang, G. Lai, Y. Ni, K. Yang, J. Jiang, L. Xu, Eur. J. Org. Chem. 2011, 1736-1742; (d) Y. Li, L.-Q. Lu, S. Das, S. Pisiewicz, K. Junge, M. Beller, J. Am. Chem. Soc. 2012, 134, 18325-18329; (e) N. A Clanton, T. E. Spiller, E. Ortiz, Z. Gao, J. M. Rodriguez-Poirier, A. J. DelMonte, D. E. Frantz, Org. Lett. 2021, 23, 3233-3236. 
Entry for the Table of Contents (Please choose one layout)

Layout 1:

\section{COMMUNICATION}

Text for Table of Contents

Layout 2:
Author(s), Corresponding Author(s)*

Page No. - Page No.

Title

((Insert TOC Graphic here))

\section{COMMUNICATION}

$$
\begin{aligned}
& \mathrm{R}^{\prime}=\mathrm{H} \text { or alkyl } \\
& \mathrm{R}^{\prime}
\end{aligned}
$$

An unprecedented efficient method for the reductive amination of carbonyl derivatives with $\omega$-amino fatty acids under hydrosilylation conditions was developed leading to the corresponding lactams. A variety of pyrrolidinones, piperidinones, 2azepanones were prepared in up to $95 \%$ isolated yields (29 examples).
Satawat Tongdee, Duo Wei, Jiajun Wu, Chakkrit Netkaew, and Christophe Darcel* $^{*}$

Page No. - Page No.

Synthesis of Lactams by Reductive Amination of Carbonyl Derivatives with $\omega$-Amino Fatty Acids under Hydrosilylation Conditions 